\title{
A Study on Prevalence and Distribution Of Tooth Agenesis
}

Research Article

R. Keerthana ${ }^{1}$, M. P. Santhosh Kumar $^{2 *}$, Manjari Chaudhary ${ }^{3}$

${ }^{1}$ Saveetha Dental College and Hospitals, Saveetha Institute of Medical and Technical Sciences, Saveetha University, Chennai, India.

${ }^{2}$ Reader, Department of Oral Surgery, Saveetha Dental College and Hospitals, Saveetha Institute of Medical and Technical Sciences, Saveetha University, Chennai, India.

${ }^{3}$ Senior Lecturer, Department of Oral Medicine, Saveetha Dental College and Hospitals, Saveetha Institute of Medical and Technical Sciences, Saveetha University, Chennai, India.

\section{Abstract}

Development anomalies in the number of teeth can result from distribution in the developing dental lamina of the tooth. The dental lamina may fail to proliferate leading to congenital absence of a primary or permanent tooth. The aim of the study was to access the prevalence and distribution of hypodontia in permanent dentition in Saveetha dental college and hospital. In this retrospective cross-sectional study, digital case records of all patients reported to saveetha dental college and hospital from June 2019 to March 2020 were reviewed. Demographic details of patients and tooth agenesis were recorded from digital case records, clinical photographs and radiographs. Retrieved data was analysed using IBM SPSS Software Version 23.0. Descriptive statistics and tests of association for categorical variables by Chi square tests were done and results were obtained. P value $<0.05$ was considered statistically significant. The most frequently missing tooth was mandibular central incisors (42.5\%). Prevalence of tooth agenesis was more among the age group of $13-24$ years $(50 \%)$ and the results were statistically significant $(p=0.021)$. Prevalence of tooth agenesis among the patients were similar in both males and females $(50 \%)$ and the results were statistically not significant $(\mathrm{p}=0.494)$. Within the limits of the present study the most commonly missing teeth were mandibular central incisors. In our study, tooth agenesis was predominantly present in the age group of 13-24 with no gender predilection. Prompt diagnosis of these anomalies can help plan treatment modalities at an early age to establish a functional and esthetic dentition.

Keywords: Etiology; Hypodontia; Prevalence; Supernumerary Tooth; Congenitally Missing Teeth.

\section{Introduction}

The formation of a tooth is a complex process which involves an interaction of the epithelium and the mesenchymal tissues. A lack of initiation of the development of dental lamina can result in the absence of tooth and an abnormal initiation may result in the development of a supernumerary tooth. Tooth agenesis or hypodontia is one of the most common anomalies of the human dentition, characterized by the developmental absence of one or more teeth. Many studies have reported that the prevalence of congenital absence of permanent teeth varies from 3\% to $11 \%$ among European and Asian populations [1,2]. Disorders in early stages of tooth formation may cause developmental problems or congenital absence of one or more teeth. Congenital absence of at least one tooth is a common dental anomaly. Congenitally miss- ing teeth are those that fail to erupt in the oral cavity and remain invisible on a radiograph, which implies that they are caused by disturbances during the early stages of tooth development [3-5].

Affecting both the dentitions, various alterations may occurs during the distinct stages of tooth development, causing numerical anomalies [6] if they occur in the first phase and anomalies of size, shape, structure and colour, if they occur in the other phases $[7,8]$.

The absence of teeth maybe be a result of combination of genetic and environmental factors [9] and it can also occur as an isolated condition or can be associated with a systemic condition or syndrome $[8,10]$. Environmental factors can cause tooth agenesis invasively or non-invasively [11]. Invasively due to jaw fractures,

*Corresponding Author

M. P. Santhosh Kumar,

Reader, Department of Oral Surgery, Saveetha Dental College and Hospitals, Saveetha Institute of Medical and Technical Sciences, Saveetha University, Chennai, India. Tel: +91 8903271734

E-mail: santhoshkumar@saveetha.com

Received: October 07,2020

Accepted: November 22, 2020

Published: November 27, 2020

Citation: R. Keerthana, M. P. Santhosh Kumar, Manjari Chaudhary. A Study On Prevalence And Distribution Of Tooth Agenesis. Int J Dentistry Oral Sci. 2020;7(11):1107-1110. doi: http://dx.doi.org/10.19070/2377-8075-20000220

Copyright: M. P. Santhosh Kumar 2020 . This is an open-access article distributed under the terms of the Creative Commons Attribution License, which permits unrestricted 
surgical procedures and non-invasively due to chemotherapy and radiation $[12,13]$.

Patients with tooth number anomalies, especially of the anterior teeth suffer from esthetical and functional problems and a series of treatments are required to provide a normal healthy occlusion [14]. Early detection of dental anomalies is vital to provide comprehensive treatments and prevent malocclusions $[15,16]$. The prevalence of tooth agenesis varies from $0.3 \%$ to $10.1 \%$ among various populations $[17,18]$. The pattern and distribution of the congenitally absent teeth differ in differ populations. In Chinese and Japanese population [19,20] mandibular central incisors are more commonly missing in Caucasian premolars [21-23].

Kjaer et al [24] stated the mandibular tooth agenesis is due to nerve tissue, supporting tissues and oral muscular disturbances. The beginning of the dental calcification is usually at 2-3 years old in premolars and permanent second molars [25], but the mineralisation of second premolars can be taken later [26]. This is the reason why a proper diagnosis can be decided only after 6 years in permanent dentition. The aim of the study was to assess and evaluate the prevalence of tooth agenesis using orthopantomography in our regional population.

\section{Materials and Methods}

\section{Study design and study setting}

This retrospective cross-sectional study was conducted by the department of oral and maxillofacial surgery in Saveetha dental college and hospital, Saveetha university, Chennai, to evaluate the prevalence of tooth agenesis from June 2019 to March 2020. The study was initiated after approval from the institutional review board.

\section{Study population and sampling}

Inclusion criteria for the study were all patients with congenitally missing teeth. The exclusion criteria was missing teeth due to extraction of exfoliation and with missing or incomplete data. After assessing details of 86,000 patients in the university patient data registry, consecutive case records of 40 patients who had congenitally missing teeth were included in the study and evaluated. Cross verification of data for errors was done with the help of an external examiner.

\section{Data collection and tabulation}

A single calibrated examiner evaluated the digital case records of the patients with congenitally missing teeth from June 2019 to March 2020. Demographic details like age, gender and missing teeth using orthopantomograph (OPG) were also recorded. All consecutive case records of patients with congenitally missing teeth were included in the study, their data were retrieved and tabulated.

\section{Statistical Analysis}

The collected data was validated, tabulated and analysed with Statistical Package for Social Sciences for Windows, version 23.0 (SPSS Inc., Chicago, IL, USA) and results were obtained. Categorical variables were expressed in frequency and percentage; and continuous variables in mean and standard deviation. Chi-square test was used to test associations between categorical variables. $\mathrm{P}$ value $<0.05$ was considered statistically significant.

\section{Results and Discussion}

In our study, 40 patients had congenitally missing teeth. The prevalence of congenitally missing teeth were $42.5 \%$ mandibular central incisors, 35\% maxillary lateral incisors, $15 \%$ mandibular low premolars $2.5 \%$ maxillary canines, $2.5 \%$ mandibular lateral incisors and maxillary and $2.5 \%$ mandibular lateral incisors. The most common missing teeth being mandibular lower central incisors. $(42.5 \%)$ [Figure 1]

Prevalence of tooth agenesis among the patients was more common in the age group of 13-24 (50\%) followed by 25-34 (25.5\%), $35-44$ and $45-55$ (10\%). Tooth agenesis was common in the age group 13-24 (50\%) with the most commonly missing teeth being mandibular lower central incisors and the results were statistically significant. Pearson's Chi square value $-17.84, \mathrm{p}=0.021(<0.05)$. Thus a statistically significant association was present between age and tooth agenesis.[Figure 2].

Prevalence of Tooth agenesis was similar in males and females $(50 \%)$ with the most commonly missing teeth being mandibular lower central incisors in both the genders. However on comparing the association between gender and tooth agenesis, the results were statistically not significant. Pearson's Chi-square value - 4.39;

Graph 1. Bar chart depicting the distribution of congenitally missing teeth with the most common missing teeth being mandibular lower central incisors. (42.5\%) Blue colour denotes Mandibular lower central incisors, red colour denotes Mandibular lower lateral incisors, green colour denotes Mandibular lower premolars, orange colour denotes Maxillary and mandibular lateral incisors, yellow colour denotes maxillary canines, purple colour denotes maxillary lateral incisors. $\mathrm{X}$ axis represents the congenitally missing teeth and $\mathrm{Y}$ axis represents the percentage of patients with tooth agenesis.

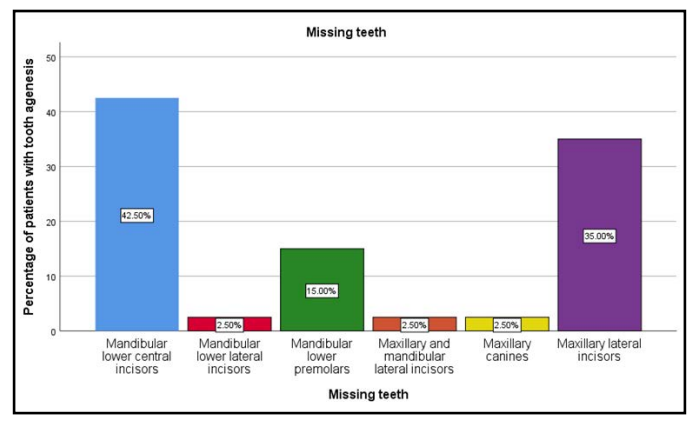


Graph 2. Bar chart depicting the association between age group and tooth agenesis. $\mathrm{X}$ axis denotes the age of the patient and $\mathrm{Y}$ axis denotes the percentage of patients with tooth agenesis. Tooth agenesis was common in the age group 13-24 $\mathbf{5 0} \%)$ with the most commonly missing teeth being mandibular lower central incisors and the results were statistically significant. Pearson's Chi square value $-17.84, \mathrm{p}=0.021(<0.05)$.

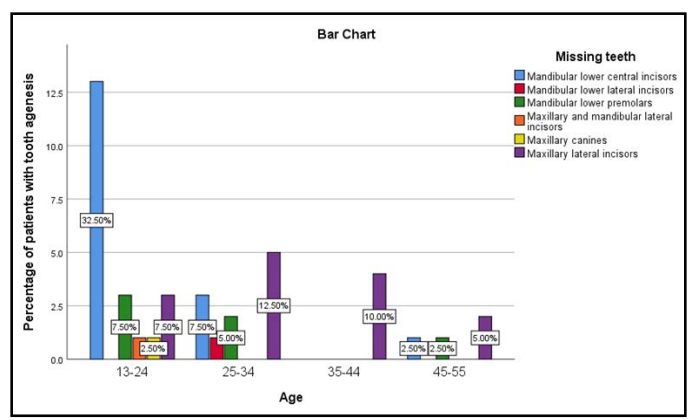

Graph 3. Bar chart depicting the association between gender and tooth agenesis. $X$ axis denotes the gender of the patient and $\mathrm{Y}$ axis denotes the percentage of patients with tooth agenesis. Prevalence of Tooth agenesis was similar in males and females with the most commonly missing teeth being mandibular lower central incisors in both the genders and the results were statistically not significant. Pearson's Chi square value $-4.39, \mathrm{p}=0.494(>0.05)$.

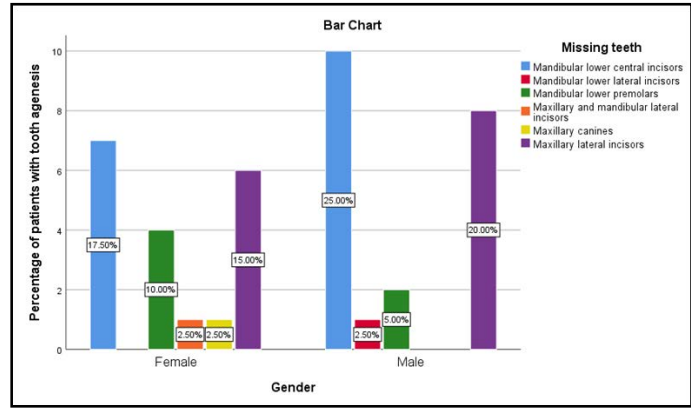

$\mathrm{p}=0.494(>0.05)$. [Figure 3].

In our study the most prevalent missing teeth were mandibular central incisors. Tooth agenesis was more common between the age group 13-24. There was a statistically significant association present between age and tooth agenesis. Tooth agenesis was equally found in both male and female gender and there was no statistically significant association seen between gender and tooth agenesis.

According to Fekonja, Gupta et al $[15,27]$ observed that mandibular central incisors were the common missing teeth followed by maxillary lateral incisors. In contrast, few studies stated that the mandibular second premolar is the most commonly missing teeth. The absence of anterior teeth in mild hypodontia is the dominant pattern, while severe hypodontia is characterized by the absence of posterior teeth. Bilateral agenesis is more frequently seen in maxillary lateral incisors. The most frequent unilateral agenesis is observed in mandibular second premolars [28].

Hypodontia is the most common developmental anomaly observed in the permanent definition. Early diagnosis and prompt intervention plays an important role in the prevention of its serious esthetical, physiological, functional and emotional complications. The etiology of congenital tooth agenesis is classified as general and local factors. General factors are a number of genetic conditions such as Down syndrome, cleft lip and palate, ectodermal dysplasia. Local factors are conditions such as trauma to the tooth germ in the early stages of development, hormonal conditions, radiation, infectious diseases and the unintentional removal of tooth germ. Diseases such as syphilis, birth injuries, and illnesses the mother has during pregnancy are also contributing fac- tors $[14,29]$. Few studies revealed that tooth agenesis is a result of a genetic mutation without a family history [30].

According to Matthews et al [17] females reported with more missing teeth. Few studies have shown results that there was no significance between gender and congenitally missing teeth [16]. The results of our study confirm Dermijian's reports who postulated that the mechanisms controlling dental development are independent of sexual and somatic maturity thus being influenced by other etiologic factors [31].

According to Hashim et al [18, 32], the common age group showing high prevalence of tooth agenesis was 15-25 years. In contrast to our study Endo $T$ et al., [19] reported the most common age group to be $7-10$ years for prevalence of missing teeth. Tooth agenesis is rarely seen in deciduous dentition although there is a relationship between hypodontia in deciduous and permanent teeth. Children showing absence in deciduous teeth are reported to show absence in permanent teeth substituting these teeth. In a study, hypodontia in deciduous dentition showed less than $1 \%$ prevalence in Caucasians, while a much higher prevalence was reported in the Japanese population. Deciduous maxillary lateral and mandibular central incisors represent $90 \%$ of the affected deciduous teeth [33].

The limitations of the study included less sample size and geographical limitation, which were to be eliminated in further studies. Thus multicentre study with large sample size should be conducted in the future.

\section{Conclusion}


Within the limits of the present study the most commonly missing teeth were mandibular central incisors. In our study, tooth agenesis was predominantly present in the age group of 13-24 with a $\mathrm{p}$ value $<0.05$ and the results were statistically significant. There was no gender predilection in this study with a $\mathrm{p}$ value $>0.5$ and the results were not statistically significant. Prompt diagnosis of these anomalies can help plan treatment modalities at an early age to establish a functional and esthetic dentition.

\section{Authors Contributions}

First author (Keerthana. R) performed the analysis, and interpretation and wrote the manuscript. Second author (Dr. Santhosh Kumar) contributed to conception, data design, analysis, interpretation and critically revised the manuscript. Third author (Dr. Manjari Chaudhary) participated in the study and revised the manuscript. All the three authors have discussed the results and contributed to the final manuscript.

\section{Acknowledgements}

We thank Saveetha Dental college for allowing us to access the patient's records and complete the research study.

\section{References}

[1]. Fekonja A. Hypodontia in orthodontically treated children. Eur J Orthod. 2005 Oct; 27(5): 457-60. PMID: 16043466. https://pubmed.ncbi.nlm. nih.gov/16043466/\#:- :text=A\%20hypodontia\%20frequency $\% 20 \mathrm{of} \% 20$ 11.3 , maxillary $\% 20$ and $\% 20$ mandibular $\% 20$ second $\% 20$ premolars.

[2]. Jesudasan JS, Wahab PU, Sekhar MR. Effectiveness of $0.2 \%$ chlorhexidine gel and a eugenol-based paste on postoperative alveolar osteitis in patients having third molars extracted: a randomised controlled clinical trial. $\mathrm{Br} \mathrm{J}$ Oral Maxillofac Surg. 2015 Nov; 53(9): 826-30. PMID: 26188932.

[3]. Tarpey P, Pemberton TJ, Stockton DW, Das P, Ninis V, Edkins S, et al. A novel Gln358Glu mutation in ectodysplasin A associated with X-linked dominant incisor hypodontia. Am J Med Genet A. 2007 Feb 15; 143(4): 390-4. PMID: 17256800.

[4]. Kumar S, Rahman RE. Knowledge, awareness, and practices regarding biomedical waste management among undergraduate dental students. Asian Journal of Pharmaceutical and Clinical Research. 2017; 10: 341.

[5]. Kumar S, Rahman RE. Knowledge, awareness, and practices regarding biomedical waste management among undergraduate dental students. Asian Journal of Pharmaceutical and Clinical Research. 2017; 10: 341.

[6]. Vijayakumar Jain S, Muthusekhar MR, Baig MF, Senthilnathan P, Loganathan S, Abdul Wahab PU, et al. Evaluation of Three-Dimensional Changes in Pharyngeal Airway Following Isolated Lefort One Osteotomy for the Correction of Vertical Maxillary Excess: A Prospective Study. J Maxillofac Oral Surg. 2019 Mar; 18(1): 139-146. PMID: 30728705.

[7]. Mostowska A, Biedziak B, Jagodzinski PP. Novel MSX1 mutation in a family with autosomal-dominant hypodontia of second premolars and third molars. Arch Oral Biol. 2012 Jun; 57(6): 790-5. PMID: 22297032.

[8]. Christabel A, Anantanarayanan P, Subash P, Soh CL, Ramanathan M, Muthusekhar MR, et al. Comparison of pterygomaxillary dysjunction with tuberosity separation in isolated Le Fort I osteotomies: a prospective, multi-centre, triple-blind, randomized controlled trial. Int J Oral Maxillofac Surg. 2016 Feb; 45(2): 180-5. PMID: 26338075.

[9]. Patturaja K, Pradeep D. Awareness of Basic Dental Procedure among General Population. Research Journal of Pharmacy and Technology. 2016; 9(9): 1349-51.

[10]. Zhu J, Yang X, Zhang C, Ge L, Zheng S. A novel nonsense mutation in PAX9 is associated with sporadic hypodontia. Mutagenesis. 2012 May; 27(3): 313-7. PMID: 22058014.
[11]. Hamosh A, Scott AF, Amberger JS, Bocchini CA, McKusick VA. Online Mendelian Inheritance in Man (OMIM), a knowledgebase of human genes and genetic disorders. Nucleic Acids Res. 2005 Jan 1; 33(Database issue): D514-7. PMID: 15608251.

[12]. Pearson MH, Williams MD. Supplemental and congenitally absent premolar teeth. Br Dent J. 1990 Jul 7; 169(1): 8. PMID: 2288573.

[13]. Packiri S, Gurunathan D, Selvarasu K. Management of Paediatric Oral Ranula: A Systematic Review. J Clin Diagn Res. 2017 Sep; 11(9): ZE06-ZE09. PMID: 29207849.

[14]. Kumar S, Snena S. Knowledge and awareness regarding antibiotic prophylaxis for infective endocarditis among undergraduate dental students. Asian J Pharm Clin Res. 2016; 9: 154-9.

[15]. Hedayati Z, Dashlibrun YN. The prevalence and distribution pattern of hypodontia among orthodontic patients in Southern Iran. Eur J Dent. 2013 Sep; 7(Suppl 1): S078-S082. PMID: 24966733.

[16]. Kumar S. Relationship between dental anxiety and pain experience during dental extractions. Asian J Pharm Clin Res. 2017; 10(3): 458-61.

[17]. Uslu O, Akcam MO, Evirgen S, Cebeci I. Prevalence of dental anomalies in various malocclusions. Am J Orthod Dentofacial Orthop. 2009 Mar; 135(3): 328-35. PMID: 19268831.

[18]. Patil SB, Durairaj D, Suresh Kumar G, Karthikeyan D, Pradeep D. Comparison of Extended Nasolabial Flap Versus Buccal Fat Pad Graft in the Surgical Management of Oral Submucous Fibrosis: A Prospective Pilot Study. J Maxillofac Oral Surg. 2017 Sep; 16(3): 312-321. PMID: 28717289.

[19]. Endo T, Ozoe R, Kubota M, Akiyama M, Shimooka S. A survey of hypodontia in Japanese orthodontic patients. Am J Orthod Dentofacial Orthop. 2006 Jan; 129(1): 29-35. PMID: 16443475.

[20]. Rao TD, Kumar MP. Analgesic Efficacy of Paracetamol Vs Ketorolac after Dental Extractions. Research Journal of Pharmacy and Technology. 2018; 11(8): 3375-9.

[21]. Abhinav RP, Selvarasu K, Maheswari GU, Taltia AA. The Patterns and Etiology of Maxillofacial Trauma in South India. Ann Maxillofac Surg. 2019 Jan-Jun; 9(1): 114-117. PMID: 31293938.

[22]. Marimuthu M, Andiappan M, Wahab A, Muthusekhar MR, Balakrishnan A, Shanmugam S. Canonical Wnt pathway gene expression and their clinical correlation in oral squamous cell carcinoma. Indian J Dent Res. 2018 MayJun; 29(3): 291-297. PMID: 29900911.

[23]. Kumar S. Knowledge, attitude and awareness of dental undergraduate students regarding HIV/AIDS patients. Asian Journal of Pharmaceutical and Clinical Research. 2017; 175.

[24]. Lin LM, Kim SG, Martin G, Kahler B. Continued root maturation despite persistent apical periodontitis of immature permanent teeth after failed regenerative endodontic therapy. Aust Endod J. 2018 Dec; 44(3): 292-299. PMID: 29336522.

[25]. Kim YH. Investigation of hypodontia as clinically related dental anomaly: prevalence and characteristics. ISRN Dent. 2011; 2011: 246135. PMID: 21991459.

[26]. Song PC, Schwartz J, Blitzer A. The emerging role of botulinum toxin in the treatment of temporomandibular disorders. Oral Dis. 2007 May; 13(3): 253-60. PMID: 17448205.

[27]. Gupta SK, Saxena P, Jain S, Jain D. Prevalence and distribution of selected developmental dental anomalies in an Indian population. J Oral Sci. 2011 Jun; 53(2): 231-8. PMID: 21712629.

[28]. Wisth PJ, Thunold K, Böe OE. Frequency of hypodontia in relation to tooth size and dental arch width. Acta Odontol Scand. 1974; 32(3): 201-6. PMID: 4155221.

[29]. AlShahrani I, Togoo RA, AlQarni MA. A review of hypodontia: classification, prevalence, etiology, associated anomalies, clinical implications and treatment options. World J Dent. 2013 Apr; 4(2): 117-25.

[30]. Guttal KS, Naikmasur VG, Bhargava P, Bathi RJ. Frequency of developmental dental anomalies in the Indian population. Eur J Dent. 2010 Jul;4(3):263-9. PMID: 20613914.

[31]. Demirjian A, Goldstein H. New systems for dental maturity based on seven and four teeth. Ann Hum Biol. 1976 Sep; 3(5): 411-21. PMID: 984727.

[32]. Hashim HA, Al-Said S. The prevalence and distribution of hypodontia in a sample of Qatari patients. J Orthod Sci. 2016 Jan-Mar; 5(1): 1-6. PMID: 26998470.

[33]. Mattheeuws N, Dermaut L, Martens G. Has hypodontia increased in Caucasians during the 20th century? A meta-analysis. Eur J Orthod. 2004 Feb; 26(1): 99-103. PMID: 14994889. 